\title{
KINETICS AND MECHANISM OF THE ELECTROCHEMICAL OXIDATION OF GRAPHITE IN BISULPHATE MELTS*
}

\author{
A. J. Arvía, W. E. Triaca and H. A. Videla \\ Instituto Superior de Investigaciones, División Electroquimica, Facultad de \\ Ciencias Exactas, Universidad Nacional de La Plata, La Plata, Argentina
}

\begin{abstract}
The kinetics of the electrochemical oxidation of graphite to volatile compounds by electrolysing molten bisulphates in the temperature range from 180 to $320^{\circ} \mathrm{C}$ has been studied by conventional steady-state and non-steady-state measurements. $\mathrm{CO}_{2}, \mathrm{CO}$ and traces of $\mathrm{SO}_{2}$ are formed during the electrochemical reaction. Assuming 4 Faraday $/ \mathrm{mol}$ of $\mathrm{CO}_{2}$ the anodic efficiency is about $90 \%$. The $\mathrm{CO}_{2} / \mathrm{CO}$ ratio is about 2 and is independent of the cd in the range considered.

The electrochemical reaction is compared to the thermal oxidation of graphite. The reaction is interpreted through a scheme involving consecutive reactions, where the rate-determining step, under Temkin conditions, is a thermal process involving a desorption of intermediates following either a first-order or second-order process depending on the type of adsorption obeyed. The activation energy derived from the rate constant at the rest potential is about $42.5 \mathrm{Kcal} / \mathrm{mol}$.
\end{abstract}

Résumó - On a étudié, en utilisant méthodes stationnaires et non-stationnaires conventionelles, la cinétique de l'oxydation électrochimique du graphite pour former des produits volatiles pendant l'électrolyse des bisulphates fondues à des témperatures de 180 a $320^{\circ} \mathrm{C}$. Dans la réaction électrochimique $\mathrm{CO}_{2}, \mathrm{CO}$ et des traces de $\mathrm{SO}_{2}$ sont formés. En supposant 4 Faraday pour chaque mole de $\mathrm{CO}_{2}$ le rendement anodique de ce dernier est d'environ $90 \%$. Le rapport $\mathrm{CO}_{2} / \mathrm{CO}$ est environ 2 indépendement de la densité de courant pour l'intervalle consideré.

On a stablié une comparison entre le réaction électrochimique et l'oxidation thermique du graphite. La réaction a été interpreté par un schéma qui comprend des réactions consécutives ou l'étape régulatrice, d'après Temkine, est un procès thermique basé sur la désorption des intermédiaires selon un procès de premier ou second ordre qui dépend du type d'adsorption observée. L'énergie d'activation dérivée de la constante de vitesse au potential de répos est d'environ $42,5 \mathrm{Kcal} / \mathrm{mol}$.

Zusammenfassung-Es wurde die Kinetik der elektrochemischen Oxydation des Graphits bei der Elektrolyse von geschmolzenem Bisulfatem untersucht. Der Temperaturbereich war von 180 bis $320^{\circ} \mathrm{C}$. Es wurden stationäre und nicht-stationäre Messmethoden verwendet. Bei der Elektrolyse wurden $\mathrm{CO}_{2}, \mathrm{CO}$ und $\mathrm{SO}_{2}$-spuren gebildet. Unter der Annahme von 4 Faraday pro mol $\mathrm{CO}_{2}$, war die Anodischeausbeute ungefähr $90 \%$. Der Mittelwert des Verhältnisses $\mathrm{CO}_{2} / \mathrm{CO}$ war $c a 2$ und unabhängig von đer Stromdichte im untersuchten Bereich.

Die elektrochemische Reaktion wird mit der thermische Oxydation von Graphit verglichen. Die Bruttoreaktion wird mittels eines Mechanismus mit einer thermischen Reaktion als Geschwindigkeitbestimmende Stufe gedeutet. Bei Temkin-Bedingungen, umfasst dieser thermische Prozess eine Desorption von Zwischenprodukten, die, abhängig von der Adsorptionsart, entweder einem Vorgang erster zweiter Ordnung gehorcht. Die von Geschwindigkeitskonstant bei Ruhespannung bestimmte Aktivierungsenergie beträgt $42,5 \mathrm{Kcal} / \mathrm{mol}$.

\section{INTRODUCTION}

GRAPHITE electrodes are very often used in molten salt electrochemistry. These electrodes are interesting from the point of view both of technical applications and theory because of the properties and well-defined structure of graphite.

From the kinetic point of view graphite electrodes offer two interesting possibilities. According to the nature of the melts they can act either as an apparently inert conducting material or they can participate in the electrode process by reacting with products or intermediate species formed during the reaction, this being of special interest in electrochemical kinetics to prove the existence of these species. As in previous studies

* Manuscript received 5 February 1969. 
of the thermal oxidation of graphite at high temperatures where the participation of different compounds of the oxide type have been demonstrated, the effect of the intermediate species on the amount of graphite electrode free surface left for the reaction and the energy changes caused by these substances can also be determined. Therefore, the kinetic study of electrode reactions involving graphite electrodes that are consumed can extend knowledge of the state of the electrode surface, particularly concerning the nature of the intermediates and their adsorption laws.

Various electrochemical reactions on graphite have been studied in this laboratory. Anodic reactions occurring with molten nitrates involve graphite electrode consumption, within the temperature range 220 to $450^{\circ} \mathrm{C} .1^{1,2}$ The same electrodes were used in nitrite melts where no consumption of the electrode was observed, ${ }^{3}$ this reaction being more similar to reactions where graphite electrodes were used in the presence of molten halides. $1-7$ The present work covers the study of the anodic reaction occurring in the electrolysis of molten potassium bisulphate and mixtures of molten potassium and sodium bisulphates. The anodic process involving these melts was recently studied on platinum electrodes ${ }^{8}$ and it was concluded that the platinum surface acted during the anodic process as a completely oxidized surface. This result led to attempt the present study because of the possibility of oxidizing graphite electrochemically in a way rather similar to the thermal oxidation of graphite at the same temperature.

\section{EXPERIMENTAL TECHNIQUE}

The electrolysis cell used was of Pyrex glass, similar to that described in an earlier publication. ${ }^{3}$ Graphite electrodes of 3- $\mathrm{mm}$ diameter and of different lengths corresponding to geometrical areas between 2 and $5 \mathrm{~cm}^{2}$ were used as anodes. The cathode consisted of a bright platinum sheet placed into a separate compartment. Two reference electrodes were employed. In the first set of experiments the reference electrode was a platinized platinum electrode dipped into the melt and continuously saturated with purified hydrogen gas at $1 \mathrm{~atm}$. In the last set of experiments an $\mathbf{A g} / \mathrm{Ag}^{+}$electrode was used. In both cases the reference-electrode compartment was connected to the working electrode by a Luggin-Haber capillary. Pure potassium bisulphate and sodium-potassium-bisulphate eutectic previously vacuum dried at room temperature in a desiccator for several weeks were used. Temperature was varied from 180 to $320^{\circ} \mathrm{C}$.

Conventional steady-state and non-steady-state measurements were made, including current/voltage curves recorded either galvanostatically or potentiostatically. In each curve the current or the potential was raised and lowered two or three times to estimate any hysteresis effect. The non-steady measurements involved the determination of build-up and decay of the electrode potential, recorded in the latter case with an oscilloscope for the shorter times and with a potentiometric recorder for the times larger than $5 \mathrm{~s}$. Details of the instrumentation used have been described in previous works. ${ }^{1.9}$

\section{Identification of reaction products}

The gaseous products of the anodic reaction were analysed by ir spectrometry. A suitable electrolysis cell, previously described, was employed for collecting gaseous products of the anodic and cathodic reactions by means of a conventional vacuum line. 
Before sampling, the electrolyte in the anodic compartment was properly saturated with reaction products. Samples were obtained either by evacuation or by passing argon or nitrogen through the anodic compartment.

$\mathrm{CO}_{2}$ and $\mathrm{CO}$ were identified as the main reaction products of the anodic reaction. $\mathrm{SO}_{2}$ was also observed in their spectrum. Quantitative evaluation of the products was made in the way usual for ir spectrometry.

Anodic efficiency

To determine the number of electrons related to each mole of product, coulometric determinations were made. $\mathrm{CO}_{2}$ was collected by passing the gases through a series of weighed traps containing Ascarite and calcium chloride. Nitrogen was employed as carrier gas for the purpose. The gases were previously cooled to $-78^{\circ} \mathrm{C}$ to condense any acid gases formed during the reaction. Blank runs were also made to correct for any impurity contained in the carrier gas.

As the reaction proceeded, a consumption of the graphite electrode was observed, best noticed at the higher electrolysis currents. Blank runs without electrolysis performed in the presence of argon and in the absence of any reacting gases as oxygen, carbon dioxide etc, showed no appreciable consumption of the graphite electrode under these conditions.

The quantitative analysis results of the anodic gases are shown in Table 1. It is interesting to notice that the ratio between $\mathrm{CO}_{2}$ and $\mathrm{CO}$ is about 2 and no conclusive dependence of this figure on current density was observed at least between the range of $0.8 \times 10^{-3}$ to $45 \times 10^{-3} \mathrm{~A} / \mathrm{cm}^{2}$.

TABle 1.*

\begin{tabular}{cccc}
\hline Sample & $\begin{array}{c}i \\
\mathrm{~mA} / \mathrm{cm}^{2}\end{array}$ & $\mathrm{CO}_{2} / \mathrm{CO}$ & $\mathrm{CO}_{2} / \mathrm{SO}_{2}$ \\
\hline 1 & $0 \cdot 105$ & $1 \cdot 50$ & - \\
2 & $0 \cdot 835$ & $2 \cdot 68$ & $39 \cdot 0$ \\
3 & 3.95 & $2 \cdot 33$ & $60 \cdot 0$ \\
4 & $7 \cdot 30$ & $2 \cdot 19$ & 142 \\
5 & $10 \cdot 5$ & $1 \cdot 98$ & $41 \cdot 5$ \\
6 & $44 \cdot 7$ & $2 \cdot 24$ & $11 \cdot 7$
\end{tabular}

* Samples 1, 2, 4 and 6 were obtained by passing argon through the anodic compartment. Samples 3 and 5 were collected by evacuation.

The ratio between $\mathrm{CO}_{2}$ and $\mathrm{SO}_{2}$ is also presented in Table 1. These results indicate that a reduction of $\mathrm{SO}_{3}$ or any anion containing $\mathrm{SO}_{3}$ groups by $\mathrm{CO}$, yielding $\mathrm{CO}_{2}$ and $\mathrm{SO}_{2}$ is negligible. Consequently the main gaseous reaction products are $\mathrm{CO}_{2}$ and $\mathrm{CO}$, be they either electrochemically or thermally produced.

To calculate the efficiency of the anodic reaction two possibilities are considered (i) the products of the electrochemical reaction are $\mathrm{CO}_{2}$ and $\mathrm{CO}$ (ii) the product of the electrochemical reaction is $\mathrm{CO}_{2}$. For case (i), taking into account that the ratio $\mathrm{CO}_{2} / \mathrm{CO}$ is about 2, $10 \mathrm{~F}$ are required for the formation of 3 moles of products, while for (ii) $4 \mathrm{~F}$ are required for each mole of $\mathrm{CO}_{2}$ formed.

If the first possibility is assumed, the anodic efficiency with respect to $\mathrm{CO}_{2}$ would always be higher than $100 \%$, which is quite improbable. If the anodic efficiency is evaluated according to possibility (ii), the result is about $90 \%$, Table 2 . Thus, the 
TABLE 2.

\begin{tabular}{ccc}
\hline $\begin{array}{c}\text { Temp. } \\
{ }^{\circ} \mathrm{C}\end{array}$ & $\begin{array}{c}i \\
\mathrm{~mA} / \mathrm{cm}^{2}\end{array}$ & $\begin{array}{c}\text { Anodic efficiency } \\
\%\end{array}$ \\
\hline 240 & $6 \cdot 80$ & 90 \\
252 & $7 \cdot 90$ & 99 \\
265 & $0 \cdot 69$ & 84 \\
265 & $4 \cdot 20$ & 94 \\
266 & $2 \cdot 05$ & 81 \\
267 & $3 \cdot 50$ & 91 \\
267 & $2 \cdot 10$ & 94 \\
268 & $3 \cdot 50$ & 94 \\
\hline
\end{tabular}

second possibility seems more reasonable since for a $\mathrm{CO}_{2} / \mathrm{CO}$ ratio of 2 , the anodic efficiency for $\mathrm{CO}_{2}$ must be $80 \%$. Although it is known that the spontaneous oxidation of graphite in the presence of gases such as $\mathrm{CO}_{2}$ also occurs, this reaction is important only at higher temperatures. ${ }^{10}$ Therefore the formation of $\mathrm{CO}$, in the temperature range of $180-320^{\circ} \mathrm{C}$ is due to a different process, which is discussed further on.

\section{Current/voltage curves}

Current/voltage curves show a linear relationship between overvoltage and logarithm of cd, Fig. 1. The overpotential $\eta$ is defined as the difference between the electrode potential related to the $\mathrm{cd} i$, and the rest potential of the graphite electrode when no net current flows. The pseudo-ohmic overvoltage correction has been included. The cd has been calculated taking the apparent electrode area. In the whole range of current investigated a satisfactory Tafel line is observed, particularly for

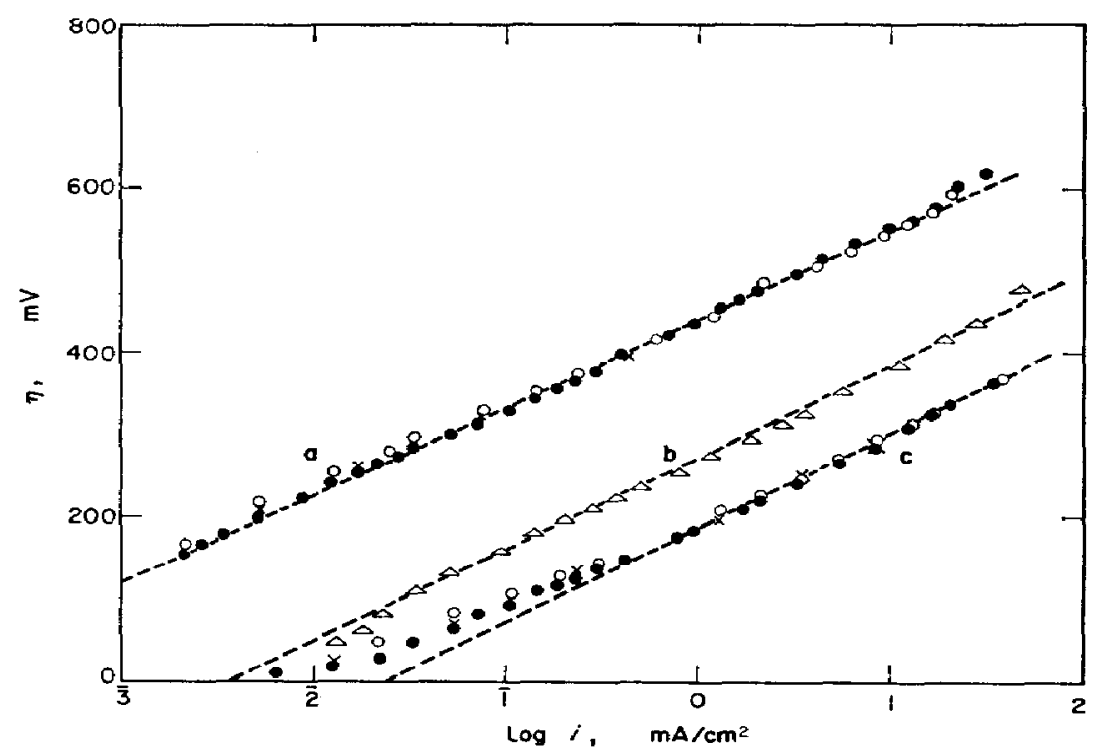

Fig. 1. Current/voltage curves at different temperatures. a, $235^{\circ} \mathrm{C} ; \mathrm{b}, 291^{\circ} \mathrm{C} ; \mathrm{c}, 320^{\circ} \mathrm{C}$.

Symbols correspond to changing the current: $\bullet, \triangle$ upwards; $O$ downwards; $\times$ cycling upwards. 
experiments performed at low temperatures. Current/voltage curves were obtained changing either the current or the potential upwards or downwards, when the experiments were made either galvanostatically or potentiostatically.

In the whole range of temperature the first current/voltage curve recorded by changing the current upwards gives, for any fixed value of $i$, a value of $\eta$ lower than that observed when the current was lowered. The same effect may be referred to a fixed potential by comparing the corresponding cds. This hysteresis effect is not appreciable at the lower temperatures but becomes larger at the higher.

When current/voltage curves were recorded either by waiting a long time between readings or after repeated cycles, the hysteresis disappeared. This is a clear indication that a steady composition of the electrode surface had been reached after a prolonged electrolysis. From the Tafel lines the experimental Tafel slope, $b_{T}$, and the apparent $\mathrm{cd} i_{0}$, at $\eta=0$, were evaluated. These figures are assembled in Table 3 and for the sake of comparison the values of the ratio $2 \cdot 3(R T / F)$ at different temperatures were also included.

TAble 3. KINETHC Parameters from $E / i$ curves

\begin{tabular}{cccc}
$\begin{array}{c}\text { Temp. } \\
{ }^{\circ} \mathrm{C}\end{array}$ & $\begin{array}{c}b_{\mathrm{T}} \\
\mathrm{mV}\end{array}$ & $\begin{array}{c}2 \cdot 3(R T / F) \\
\mathrm{mV}\end{array}$ & $\begin{array}{c}i_{\mathbf{0}} \times 10^{8} \\
\mathrm{~A} / \mathrm{cm}^{2}\end{array}$ \\
\hline 186 & $101 \pm 5$ & $91 \cdot 0$ & 0.071 \\
231 & 100 & $100 \cdot 0$ & 3.98 \\
235 & 108 & $100 \cdot 9$ & 7.60 \\
290 & 110 & 111.7 & 478 \\
291 & 112 & 112.0 & 354 \\
320 & 118 & 117.7 & 2300 \\
\hline
\end{tabular}

Figure 1 (c) shows a typical current/voltage curve obtained at $320^{\circ} \mathrm{C}$. The plot shows a departure from the Tafel line at lower overvoltages. This effect is probably due to the magnitude of the overvoltage concerned, although we should not discard a probable interference of the product formed during the thermal decomposition of the melt, which is rather appreciable at this temperature.

The temperature effect on current/voltage curves is a very sensitive decrease of overvoltage with increasing temperature. The effect is reflected in the increase of the $i_{0}$ values when increasing the temperature. By plotting $\log i_{0}$ against $1 / T$ a good Arrhenius plot is obtained. From the slope of this plot the average experimental activation energy is $42.5 \pm 5 \mathrm{Kcal} / \mathrm{mole}$.

\section{Decay of emf at current interruption}

After interrupting the electrolysis current the emf decay follows the already known law predicted for electrochemical processes under activation control, the emf decaying linearly with the logarithm of time. Typical emf decay curves are shown in Figs. 2, 3 and 4.

At the lowest temperatures the emf-decay curves present a linear region covering about three logarithmic decades. As the temperature increases, immediately after the current interruption, the emf tends to stay at nearly a constant value for a rather long time, and at slightly longer times the plot approaches a linear relationship in the $\eta / \log t$ diagram, involving a slope close to $2 \cdot 3(R T / F)$. Between 190 and $290^{\circ} \mathrm{C}$ there is always a good range in the $\eta / \log t$ plot where a $2 \cdot 3(R T / F)$ slope is obtained. 


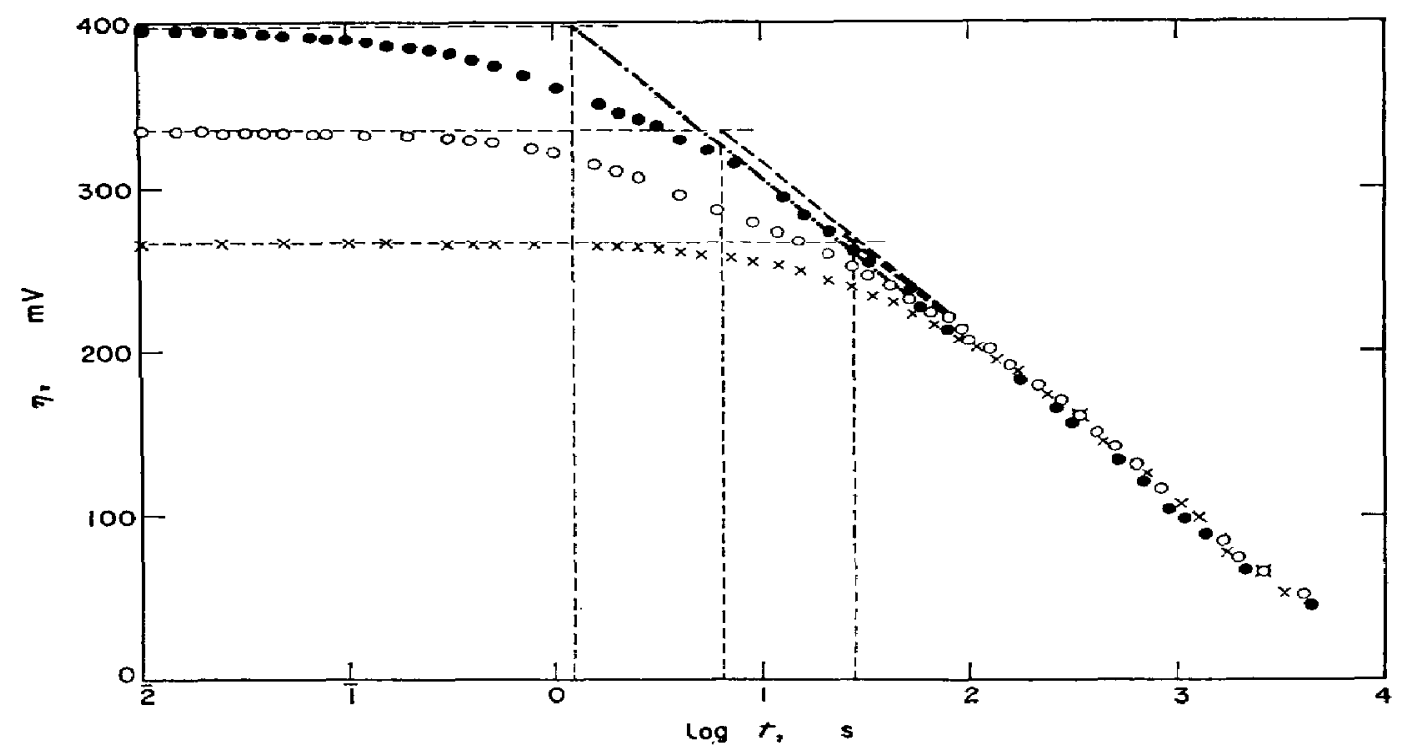

Fig. 2. Semilogarithmic plot of emf decay at current interruption. $232^{\circ} \mathrm{C}$. Cd at interruption: $0,0.208 \times 10^{-3} \mathrm{~A} / \mathrm{cm}^{2} ; O 0.416 \times 10^{-4} \mathrm{~A} / \mathrm{cm}^{2} ; \times, 0.145 \times 10^{-4}$ $A / \mathrm{cm}^{2}$. $t^{\prime}$ 'values are indicated in the figure.

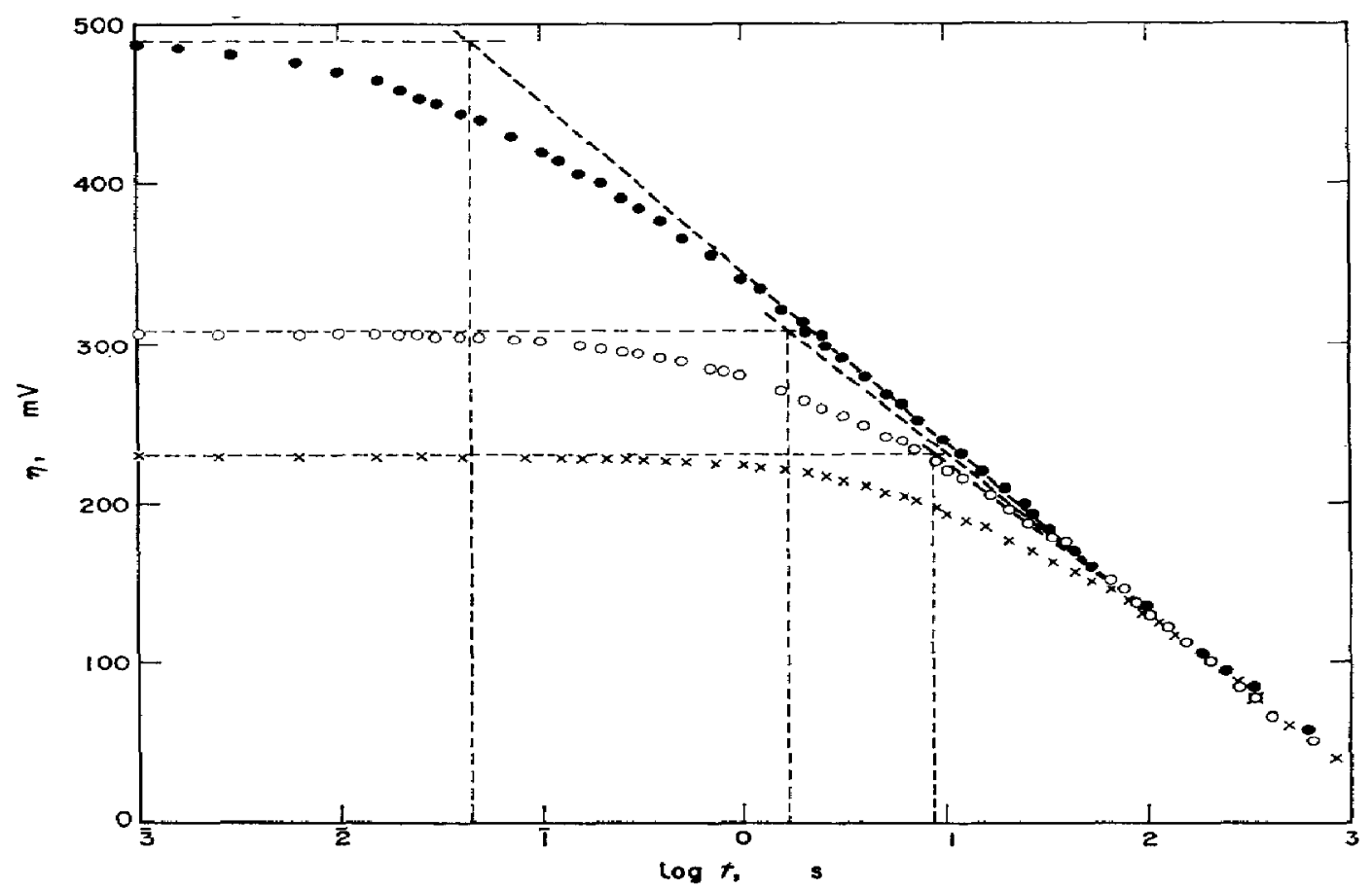

FIG. 3. Semilogarithmic plot of emf decay at current interruption. $263^{\circ} \mathrm{C}$. $0,5.85 \times 10^{-3} \mathrm{~A} / \mathrm{cm}^{2} ; 0,0.254 \times 10^{-3} \mathrm{~A} / \mathrm{cm}^{2} ; \times, 0.51 \times 10^{-4} \mathrm{~A} / \mathrm{cm}^{2}$. 


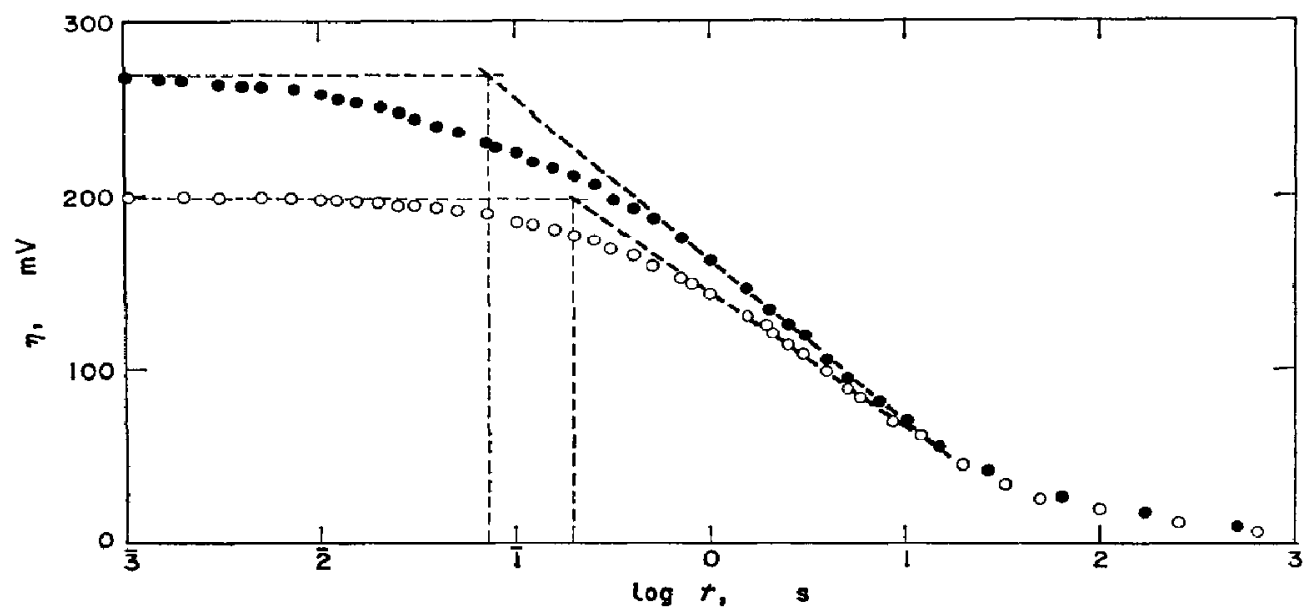

FIG. 4. Semilogarithmic plot of emf decay at current interruption. $320^{\circ} \mathrm{C}$. - $5.21 \times 10^{-3} \mathrm{~A} / \mathrm{cm}^{2} ; 0,1.04 \times 10^{-3} \mathrm{~A} / \mathrm{cm}^{2}$

In the temperature range from 290 to $320^{\circ} \mathrm{C}$ the semilogarithmic plot shows a more extended initial range where the emf does not change appreciably, and the linear region involving the above-mentioned slope covers only one logarithmic decade. Furthermore the slope $2 \cdot 3(R T / F)$ in these experiments is approached only with experiments performed at the highest cds. At low cds the slope of the linear portion is usually slightly lower. These results, however, must be considered taking into account the magnitude of the emf decay observed at higher temperatures, which is certainly much lower than that observed at lower temperatures. These results from the transient experiments agreed satisfactorily well with the results obtained under steady-state conditions.

At the lower temperatures it is observed that the emf-decay slope, $b_{\mathrm{d}}$, is independent of the current used in the previous electrolysis, as is concluded from data assembled in Table 4. Contrarily to the experiments at higher temperatures the slope depends on the initial value of $i$, approaching the value $2 \cdot 3(R T / F)$ at high initial currents.

From the $t^{\prime}$ value obtained from the interception of the emf-decay slope with the initial potential, the electrode capacitance, $C$, at overvoltage $\eta$ was evaluated.11 Data obtained from decay curves are assembled in Table 4 . The electrode capacitances are large, their magnitude being related quite likely to an appreciable contribution of the electrode roughness, because of the consumption of the electrode. The electrode capacitance values go from about $3 \times 10^{3} \mu \mathrm{F} / \mathrm{cm}^{2}$ up to a maximum value of about $10^{4} \mu \mathrm{F} / \mathrm{cm}^{2}$.

A slight dependence of the electrode capacitance on potential is observed, particularly at the low overvoltage region and at the highest one. The lower values are obtained at the rest potential and beyond $0.6 \mathrm{~V}$. There is an intermediate overvoltage region covering about $0.3 \mathrm{~V}$ where the capacitance does not change appreciably with the overvoltage. At the lower temperatures the capacitance decreases with the electrode potential, while the reverse effect is observed at the highest temperatures. Figure 5 shows the electrode capacitance dependence on the overvoltage for one emf-decay experiment, the electrode capacitance being calculated by the differential method.11 As the data presented in Fig. 5 correspond to an electrode surface probably involving a constant roughness factor, their dispersion is appreciably lower than that reported in Table 4. 


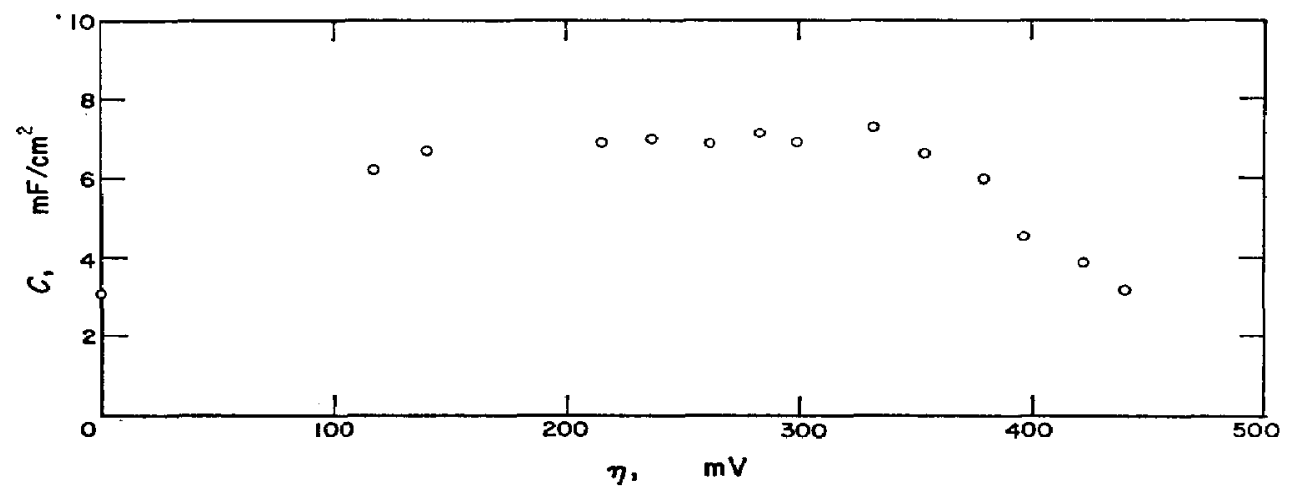

FIG. 5. Dependence of electrode capacitance on potential from the analysis of the whole decay curve. $232^{\circ} \mathrm{C} ; i=1.04 \times 10^{-3} \mathrm{~A} / \mathrm{cm}^{2}$

TABle 4. Kinetic DATA OBTAINED From EMF DECAY

\begin{tabular}{|c|c|c|c|c|c|c|}
\hline Temp. & $\stackrel{i}{\mathrm{~mA} / \mathrm{cm}^{2}}$ & $\stackrel{\eta}{m V}$ & $\underset{\mathrm{mV}}{b_{\mathbf{a}}}$ & $\underset{\mathrm{mV}}{2 \cdot 3(R T / F)}$ & $t^{\prime}$ & $\underset{\mu \mathrm{F} / \mathrm{cm}^{2}}{C}$ \\
\hline $\begin{array}{l}232 \\
232 \\
232 \\
232 \\
232 \\
232\end{array}$ & $\begin{array}{l}0 \cdot 0145 \\
0 \cdot 0416 \\
0 \cdot 104 \\
0 \cdot 208 \\
1 \cdot 04 \\
5 \cdot 21\end{array}$ & $\begin{array}{l}267 \\
336 \\
356 \\
398 \\
472 \\
560\end{array}$ & $\begin{array}{l}100 \pm 5 \\
100 \\
103 \\
104 \\
108 \\
114\end{array}$ & $\begin{array}{l}100 \cdot 0 \\
100 \cdot 0 \\
100 \cdot 0 \\
100 \cdot 0 \\
100 \cdot 0 \\
100 \cdot 0\end{array}$ & $\begin{array}{l}28 \cdot 2 \\
6 \cdot 46 \\
2 \cdot 95 \\
1 \cdot 20 \\
0.166 \\
0.030\end{array}$ & $\begin{array}{l}9400 \\
6150 \\
6850 \\
5520 \\
3680 \\
3100\end{array}$ \\
\hline $\begin{array}{l}263 \\
263 \\
263 \\
263 \\
263 \\
263\end{array}$ & $\begin{array}{l}0 \cdot 051 \\
0 \cdot 254 \\
1 \cdot 27 \\
1 \cdot 27 \\
5 \cdot 85 \\
7 \cdot 62\end{array}$ & $\begin{array}{l}230 \\
309 \\
355 \\
355 \\
490 \\
530\end{array}$ & $\begin{array}{l}98 \\
101 \\
106 \\
107 \\
106 \cdot 5 \\
106 \cdot 5\end{array}$ & $\begin{array}{l}106 \cdot 3 \\
106 \cdot 3 \\
106 \cdot 3 \\
106 \cdot 3 \\
106 \cdot 3 \\
106 \cdot 3\end{array}$ & $\begin{array}{l}8.50 \\
1.66 \\
0.309 \\
0.339 \\
0.045 \\
0.036\end{array}$ & $\begin{array}{l}9950 \\
9600 \\
8510 \\
9250 \\
5610 \\
5950\end{array}$ \\
\hline $\begin{array}{l}290 \\
290 \\
290 \\
290 \\
290\end{array}$ & $\begin{array}{l}0 \cdot 0416 \\
0 \cdot 104 \\
0 \cdot 208 \\
1 \cdot 04 \\
5 \cdot 21\end{array}$ & $\begin{array}{l}166 \\
196 \\
218 \\
275 \\
341\end{array}$ & $\begin{array}{r}74 \\
85 \\
92 \\
98 \\
101\end{array}$ & $\begin{array}{l}111 \cdot 7 \\
111 \cdot 7 \\
111 \cdot 7 \\
111 \cdot 7 \\
111 \cdot 7\end{array}$ & $\begin{array}{l}5 \cdot 25 \\
2 \cdot 63 \\
1 \cdot 82 \\
0 \cdot 389 \\
0 \cdot 080\end{array}$ & $\begin{array}{l}6800 \\
7400 \\
9480 \\
9500 \\
9450\end{array}$ \\
\hline $\begin{array}{l}320 \\
320 \\
320\end{array}$ & $\begin{array}{l}0 \cdot 208 \\
1 \cdot 04 \\
5 \cdot 21\end{array}$ & $\begin{array}{l}129 \\
198 \\
269\end{array}$ & $\begin{array}{l}61 \\
76 \\
93\end{array}$ & $\begin{array}{l}117 \cdot 7 \\
117 \cdot 7 \\
117 \cdot 7\end{array}$ & $\begin{array}{l}0 \cdot 833 \\
0 \cdot 200 \\
0 \cdot 074\end{array}$ & $\begin{array}{l}6540 \\
6300 \\
9550\end{array}$ \\
\hline
\end{tabular}

\section{Build-up curves}

From the initial slope of the build-up curves obtained under different experimental conditions, the electrode capacitance at the rest potential is obtained in the usual way. ${ }^{11}$ The average electrode capacitance is over $3 \times 10^{3} \mu \mathrm{F} / \mathrm{cm}^{2}$, and is temperatureindependent. Taking into account that at the rest potential, and in the absence of any reacting gas, the corrosion of the electrode is negligible, this figure can be used to estimate the electrode roughness factor, as $c a 10^{2}$.

\section{DISCUSSION}

The electrochemical oxidation of graphite in bisulphate melts is a process closely related to the thermal oxidation of graphite in the presence of oxygen and other oxidizing gases such as ozone or carbon dioxide. The thermal oxidation of graphite has been studied in detail, both from the thermodynamic and kinetic standpoints. ${ }^{10}$ 
In the thermal reaction the role played by different surface groups and surface oxides has been shown, and the subject has been reviewed recently. ${ }^{12}$

The electrochemical reaction is characterized as an activated electrode process, since over a wide range of cd the current/potential curves fit a Tafel line with a slope equal to $2 \cdot 3 R T / F$ and the apparent cd extrapolated to $\eta=0$ is of order of magnitude characteristic of a slow electrochemical reaction. Furthermore, the average experimental activation energy is much larger than that usually found in electrode processes. In the non-steady measurements a satisfactory linear $\eta / \log t$ plot is obtained from emfdecay curves, with slopes coinciding with the Tafel slopes. The agreement is in principle an indication that the same reactions take place on graphite electrodes either steady or non-steady conditions.

For discussing this reaction we shall begin by giving an explanation of the Tafel slope in terms of a reaction mechanism. The main products formed during the electrochemical reaction are also produced in the thermal oxidation of graphite. The $\mathrm{CO}_{2}$ and $\mathrm{CO}$ formation takes place through one or more surface oxides and eventually through the participation of intermediate oxygen complexes on the graphite surface related to them. ${ }^{13}$ To interpret the electrode reaction we must first decide if the reaction intermediates of the oxide type obey either a Langmuir or a Temkin isotherm. As a diagnostic criterion of the type of adsorption, we must try to correlate results obtained by electrochemical measurements with those obtained in the chemisorption of gases on carbon. The chemisorption of different gases on carbon involves the coverage of only a small fraction of the total surface. This conclusion was clearly established, for instance, for oxygen adsorption on graphite..$^{14-16}$ Thus, at $200^{\circ} \mathrm{C}$, the oxygen surface coverage on amorphous carbon is about $6 \%$. At $300^{\circ} \mathrm{C}$ the amount of chemisorbed oxygen on Graphon, previously subjected to burn-off, constitutes only about 5 $\%$ of the BET area. Consequently, the number of sites on which a higher state of oxidation can be achieved yielding $\mathrm{CO}_{2}$ and $\mathrm{CO}$, is rather small. This means that the degree of surface coverage must be lower than $0 \cdot 1$ in the conditions prevailing during the thermal oxidation, as well as on graphite electrodes when no applied potential exists.

The decay slopes and the electrode capacitances calculated from $t^{\prime}$, over a large range of potential, are nearly independent of the potential at the current interruption. However, for interpreting the total electrode capacitance two different contributions must at least be distinguished. (i) there is a non-faradaic term the value of which is of the order of $3 \times 10^{3} \mu \mathrm{F} / \mathrm{cm}^{2}$ independent of temperature. It gives an idea of the actual active electrode area. This capacitance was measured at the rest potential, where the situation must be directly compared to the conditions prevailing during thermal oxidation, so a low degree of coverage is admitted; (ii) there is a faradaic contribution to the capacitance due to the accumulation of intermediates on the electrode surface because of the electrode reaction. This is generally potentialdependent, reaching a maximum value when the degree of surface coverage is 0.5 . The electrode capacitance determined at the rest potential agrees with the value obtained for the limiting case of a degree of coverage equal to one, as previously assumed in the electrochemical oxidation of nitrates on graphite electrodes at the same temperature. ${ }^{2}$

Therefore, the behaviour of the electrode capacitance with potential resembles the case of an electrode process where intermediate compounds are formed during the 
reaction obeying a Temkin isotherm rather than a Langmuir, involving an appreciably large rate of change of the free energy of adsorption with degree of coverage. On the basis of this explanation the coincidence of the steady Tafel slopes with the emf-decay slopes is immediately deduced. ${ }^{17}$

On the assumption that the Temkin isotherm is obeyed by the reaction intermediates, and considering that the process on steady conditions is the same as that taking place in the transients, we can postulate the probable reaction path yielding $\mathrm{CO}_{2}$. As a unique slope exists in the whole range of potential investigated, it is reasonable to interpret the kinetics of the reaction with a scheme of consecutive reactions. As Langmuir adsorption is discarded, we cannot consider any reaction mechanism involving electron-transfer reactions as rate-determining step. Neither is there an explanation for the slope $2 \cdot 3(R T / F)$ under the limiting conditions derived from a Langmuir isotherm. ${ }^{18}$

Another possibility which is in principle also discarded is the participation as ratedetermining step of any reaction involving the simultaneous transfer of two electrons.

The interpretation of experimental results in terms of a mechanism of intermediate surface diffusion is also discarded because of the results obtained in recent studies of oxygen chemisorption on carbon. ${ }^{19.20}$ There it was found that the experimental entropy of activation for this process was 39 eu in agreement with the value predicted by absolute reaction-rate theory, assuming an immobile activated complex having in the most favorable conditions a limited degree of free rotation.

\section{Probable mechanism of reaction for $\mathrm{CO}_{2}$ formation}

As graphite contains different types of carbon-oxygen groups, let us firstly suppose that the formation of $\mathrm{CO}_{2}$ involves the participation of a partially oxidized surface; structural details concerning the oxidized graphite participating in the reaction are momentarily disregarded. Thus, we have the following scheme of consecutive reactions,

$$
\begin{aligned}
\text { Graphite }+\mathrm{HSO}_{4}^{-} & =\text {Graphite }\left(\mathrm{HSO}_{4}\right)+\mathrm{e} \\
\text { Graphite }\left(\mathrm{HSO}_{4}\right) & =\text { Graphite }(\mathrm{O})+\mathrm{SO}_{2}+\mathrm{H}^{+}+\mathrm{e}, \\
\text { Graphite }(\mathrm{O})+\text { Graphite }(\mathrm{O}) & =\mathrm{CO}_{2}+\text { Graphite. }
\end{aligned}
$$

This reaction scheme is a rather simple one since only two intermediates, one containing the radical $\mathrm{HSO}_{4}$ and another containing an oxygen atom attached to the graphite are supposed. The product formed in the first reaction may be considered as a kind of "graphite bisulphate". Actually graphite bisulphate has been formed under different circumstances. ${ }^{21}$ Both intermediates are produced in steps comprising a transfer of one electron and the $\mathrm{CO}_{2}$ formation is due to a thermal reaction of two radicals, according to step $3 \mathrm{~A}$. The kinetic analysis of this mechanism in terms of Temkin conditions, assuming that the activity of bisulphate ions is unity, gives the following rate equations for steps $1 \mathrm{~A}$ to $3 \mathrm{~A}$,

$$
\begin{aligned}
v_{1} & =k_{1}(1-X) \exp \left\{-\left[\Delta G_{1}{ }^{*}+(1-\gamma) r_{2} X-\beta F E\right] / R T\right\}, \\
v_{-1} & =k_{-1} a_{1} \exp \left\{-\left[\Delta G_{-1}{ }^{*}-\gamma r_{2} X+(1-\beta) F E\right] / R T\right\}, \\
v_{2} & =k_{2} a_{1} \exp \left\{-\left[\Delta G_{2}{ }^{*}-\gamma r_{1} X+(1-\gamma) r_{2} X-\beta F E\right] / R T\right\}, \\
v_{-2} & =k_{-2} a_{2} a_{\mathrm{SO}_{3}} a_{\mathrm{H}^{+}} \exp \left\{-\left[\Delta G_{-2}{ }^{*}+(1-\gamma) r_{1} X-\gamma r_{2} X+(1-\beta) F E\right] / R T\right\}, \\
v_{3} & =k_{3} a_{2}{ }^{2} \exp \left\{-\left[\Delta G_{3}{ }^{*}-2 \gamma r_{1} X\right] / R T\right\}
\end{aligned}
$$


Here $v_{i}$ is the velocity of the step $\mathrm{i}$ and $k_{\mathrm{i}}$ its specific rate constant, $a_{\mathrm{i}}$ is the surface activity of the reacting intermediate and $X$ is the total degree of surface coverage. $\Delta G_{i}{ }^{*}$ is the molar free energy of activation of adsorption for step $i$. $r_{1}$ and $r_{2}$ refers to the rate of change of the free energy of adsorption with degree of coverage and the sub-indices 1 and 2 applied for adsorbed reactives and products in each step in the anodic direction respectively. $\gamma$ is a symmetry factor for the adsorption co-ordinate and $\beta$ is the symmetry factor for the reaction co-ordinate related to each step of the electrochemical reaction. $E$ is the potential applied at the interface.

From the kinetic standpoint none of the steps $1 \mathrm{~A}$ and $2 \mathrm{~A}$ may be considered as rate-determining because they are related to Tafel slopes equal to $2 \cdot 3(2 R T / F)$, if the symmetry factors are taken equal to $0 \cdot 5$. The only possibility is then restricted to step 3A. If it is assumed that the preceding steps are in quasi-equilibrium, that is $v_{1}=v_{-1}$ and $v_{2}=v_{-2}$, then:

$$
r_{\mathbf{i}} X=K_{\mathbf{1}}+F E \text {. }
$$

That is, the degree of coverage by reactants in any rate-determining step will give the same dependence of the product $r_{1} X$ on potential, except for the constant $K_{1}$, which comprises a different ratio of rate constants according to the step which is considered.

Another reasonable assumption is to admit that in any step the rate of change of the free energy of adsorption with degree of coverage for the reaction in the forward direction is approximately the same as for the reverse direction $\left(r_{1} \approx r_{2}\right)$. Under these conditions, if step $3 \mathrm{~A}$ is rate-determining, this being the only one that under Temkin conditions yields a theoretical Tafel slope lower than $2 \cdot 3(2 R T / F)$, the rate equation assuming the quasi-equilibrium of the preceding steps, becomes

$$
v_{3}=k_{3} a_{2}^{2} \exp \left(-\Delta G_{3}{ }^{*} / R T\right) \exp \left(2 \gamma K_{1} / R T\right) \exp (2 \gamma F E / R T)=K^{\prime} \exp (2 \gamma F E / R T) \text {. }
$$

According to (7), if the adsorption is a non-activated process $(\gamma=1)$ the Tafel slope turns out to be $2 \cdot 3(R T / 2 F)$, while for the case of activated adsorption $(\gamma=0 \cdot 5)$, the Tafel slope results $2 \cdot 3(R T / F)$.

Another simple reaction scheme involving the initial participation of oxidized graphite can also be postulated. The existence of a certain degree of surface oxidation on graphite when the steady state has been reached in the electrode reaction is evidenced by the hysteresis observed at low cd through the current/voltage curves. This effect can be explained by assuming that an appreciable time is required to reach a rather high degree of surface oxidation. This effect has been earlier observed by employing graphite electrodes in cryolite melts. ${ }^{22,23}$ Then, let us write the following reaction scheme:

$$
\begin{aligned}
& \text { Graphite-O }+\mathrm{HSO}_{4}^{-}=\text {Graphite }\left[\begin{array}{l}
(\mathrm{O}) \\
\left(\mathrm{HSO}_{4}\right)
\end{array}\right]+\mathrm{e}, \\
& \text { Graphite }\left[\begin{array}{l}
(\mathrm{O}) \\
\left(\mathrm{HSO}_{4}\right)
\end{array}\right]=\text { Graphite }\left[\begin{array}{l}
(\mathrm{O}) \\
(\mathrm{O})
\end{array}\right]+\mathrm{SO}_{3}+\mathrm{H}^{+}+\mathrm{e}, \\
& \text { Graphite }\left[\begin{array}{l}
(\mathrm{O}) \\
(\mathrm{O})
\end{array}\right]=\text { Graphite }+\mathrm{CO}_{2}, \\
& \text { [Graphite }+\mathrm{HSO}_{4}^{-} \rightarrow \text { Graphite }-\mathrm{O}+\mathrm{SO}_{3}+\mathrm{H}^{+}+2 \text { e] }
\end{aligned}
$$


Step $1 \mathrm{~B}$ comprises the discharge of a bisulphate ion on the oxidized graphite surface yielding a short-life surface intermediate involving the radical $\mathrm{HSO}_{4}$. For energetic reasons we postulate that the active sites for the electron transfer during the anodic reaction are located in adjacent positions with respect to oxidized sites. Step 2B corresponds to the intermediate electrochemical decomposition and formation of a more stable intermediate which decomposes according to step 3B by a first-order process. The surface oxide is regenerated according to reaction $4 \mathrm{~B}$, or any other similar process involving the participation of two electrons, fitting the stoichiometry of the total reaction. Reaction $4 \mathrm{~B}$ has to be a fast process having a negligible effect on the kinetics of the electrode reaction. On the basis of previous discussion of scheme A, let us now consider that step $3 B$ is rate-determining. Then, the rate equation is

$$
v_{3}=k_{3} a_{3} \exp \left(-\Delta G_{3}{ }^{*} / R T\right) \exp \left(\gamma K_{1} / R T\right) \exp (\gamma E F / R T)=K^{\prime \prime} \exp (\gamma E F / R T) .
$$

Again two limiting cases can be derived from (8). If the adsorption of the intermediate is a non-activated process $(\gamma=1)$ the theoretical Tafel slope is equal to $2 \cdot 3(R T / F)$, and for an activated adsorption process $(\gamma=0.5)$, the theoretical Tafel slope is $2 \cdot 3(2 R T / F)$.

Let us turn now to an interpretation which is based upon possible structural aspects of intermediates involved in the reaction path. Thus, taking into account previous assumptions involved in schemes $A$ and $B$ and also that $4 F$ are required for one mole of $\mathrm{CO}_{2}$ produced, the following reaction may occur,

$$
\begin{aligned}
& \text { Graphite-O }+\mathrm{HSO}_{4}^{-}=\int_{\left(\mathrm{HSO}_{4}\right)}^{(\mathrm{O})}+\mathrm{e}, \\
& \int_{\left(\mathrm{HSO}_{4}\right)}^{(\mathrm{O})}=\int_{\left(\mathrm{OSO}_{3}^{-}\right)}^{(\mathrm{O})}+\mathrm{H}^{+} \text {, } \\
& \int_{\left(\mathrm{OSO}_{3}{ }^{-}\right)}^{(\mathrm{O})}=\int_{(\mathrm{O})}^{(\mathrm{O})}+\mathrm{SO}_{3}+\mathrm{e}, \\
& \left.\gamma_{(\mathrm{O})}^{(\mathrm{O})}+\mathrm{HSO}_{4}^{-}=\gamma_{\left(\mathrm{O}^{\prime}\right.}^{(\mathrm{O}} \mathrm{OSO}_{3} \mathrm{H}\right)+\mathrm{e}, \\
& \left.\left.\int_{\left(\mathrm{O}^{-}\right.}^{(\mathrm{O}} \mathrm{OSO}_{3} \mathrm{H}\right)=\int_{\left(\mathrm{O}^{-}\right.}^{(\mathrm{O}} \mathrm{OSO}_{3}^{-}\right)+\mathrm{H}^{+} \text {, } \\
& \left.\int_{\left(\mathrm{O}^{-}\right.}^{(\mathrm{O}}, \mathrm{O}_{3}^{-}=\int_{\left(\mathrm{O}^{\prime}\right.}^{(\mathrm{O}} \mathrm{O}\right)+\mathrm{SO}_{3}+\mathrm{e} \\
& \left.\int_{(\mathrm{O}}^{(\mathrm{O}} \mathrm{O}\right)=\text { Graphite-O }+\mathrm{CO}_{2} \text {. }
\end{aligned}
$$


Step $1 \mathrm{C}$ comprises the discharge of a bisulphate ion originating an intermediate which further dissociates according to step 2C. The product formed in this step is oxidized according to step $3 \mathrm{C}$, yielding as a product an oxidized graphite involving two neighboring oxygen atoms. A further discharge of bisulphate ions on these oxidized sites yields an intermediate which dissociates according to step $5 \mathrm{C}$. The product formed in this step decomposes electrochemically according to step $6 \mathrm{C}$, yielding another intermediate of peroxidic type which finally decomposes according to step $7 \mathrm{C}$, yielding $\mathrm{CO}_{2}$ and regenerating a partially oxidized graphite surface that again enters the electrode reaction. It is evident that scheme $\mathbf{C}$ comprises various electron-transfer steps which depend on the distribution of surface oxides on graphite. This means that for highly oxidized graphites the reaction may start with step $4 \mathrm{C}$, while for a nonoxidized graphite surface, an oxidation step preceding reaction $1 \mathrm{C}$ has to be added.

The interesting feature of scheme $\mathrm{C}$ is the participation of intermediates of peroxidic type which are similar to those already postulated for the mechanism of oxidation of carbon blacks by dry mixtures of oxygen and ozone. ${ }^{24}$ In the latter reaction carbon dioxide is the reaction product.

After the kinetic analysis of this mechanism in terms of a Temkin isotherm it is also concluded that any step such as those involving either electron-transfer or ionization reactions can be discarded as rate-determining steps. Considering that step $7 \mathrm{C}$ is rate determining, the rate equation results

$$
v_{7}=k_{7} a_{7} \exp \left(-\Delta G_{7}^{*} / R T\right) \exp \left(\gamma K_{\mathrm{f}} / R T\right) \exp (\gamma E F / R T)=K^{\prime \prime \prime} \exp (\gamma E F / R T)
$$

Equation (9) is formally the same as (8). Hence, the kinetic analysis of this mechanism yields a theoretical Tafel slope equal to $2 \cdot 3(R T / F)$ when the adsorption of the intermediate participating in the rate-determining step is a non-activated process.

Another possible reaction path, in principle not much different than the previous one in the absence of the dissociation reactions, is the following:

$$
\begin{aligned}
& \text { Graphite-O }+\mathrm{HSO}_{4}^{-}=\int_{\left(\mathrm{HSO}_{4}\right)}^{(\mathrm{O})}+\mathrm{e} \\
& \int_{\left(\mathrm{HSO}_{4}\right)}^{(\mathrm{O})} \\
& =\int_{(\mathrm{O})}^{(\mathrm{O})}+\mathrm{SO}_{3}+\mathrm{H}^{+}+\mathrm{e} \\
& \left.\int_{(\mathrm{O})}^{(\mathrm{O})}+\mathrm{HSO}_{4}^{-}=\int_{\left(\mathrm{O}^{-}\right.}^{(\mathrm{O}} \mathrm{OSO}_{3} \mathrm{H}\right)+\mathrm{e} \\
& \left.\left.\int_{(\mathrm{O}}^{(\mathrm{O}} \mathrm{OSO}_{3} \mathrm{H}\right)=\int_{(\mathrm{O}}^{(\mathrm{O}} \mathrm{O}\right)+\mathrm{SO}_{3}+\mathrm{H}^{+}+\mathrm{e} \\
& \int_{\left(0^{\prime}\right.}^{(0)} \\
& =\text { Graphite- } \mathrm{O}+\mathrm{CO}_{2} \text {. }
\end{aligned}
$$


In this mechanism the same intermediates already postulated in scheme $\mathrm{C}$ are assumed. The final step comprising the decomposition of the peroxidic intermediate is considered as rate-determining. The conclusion drawn from the kinetic analysis of this mechanism are the same as above mentioned for scheme $C$ with reaction $7 \mathrm{C}$ rate-determining.

If we assume that the rate-determining step is reaction $3 \mathrm{~A}$, the value of $r$ can be estimated from the capacitance/potential dependence. This value should be about $20 \mathrm{Kcal} / \mathrm{mole}$ or even higher. ${ }^{11}$ With this figure let us try to evaluate the range of potential where Temkin conditions should be obeyed. Let $E_{1}$ be the potential related to the degree of coverage $X_{1}$ and $E_{2}$ related to $X_{2}$. If the limits of Temkin isotherm are supposed in the range 0.1 to $0 \cdot 9$, the potential range is

$$
E_{2}-E_{1}=\frac{r}{F\left(X_{2}-X_{1}\right)}-\frac{R T}{F} \ln \frac{\left(1-X_{2}\right) X_{1}}{X_{2}\left(1-X_{1}\right)} .
$$

Hence, for $r=20$, Temkin conditions would prevail at about $1 \cdot 1 \mathrm{~V}$. This potential range apparently exceeds the potential range found from the electrode capacitance dependence on potential, but supports the fact that emf-decay slopes coincide with the Tafel slope in the whole range of potential investigated.

If a more complex kinetic model is assumed for interpreting these results, such as surface-induced heterogeneity, ${ }^{25,26}$ the same theoretical parameters are obtained.

From the previous discussion it follows that the reaction mechanisms proposed to explain the electrochemical oxidation of graphite in molten bisulphates are rather similar to the mechanism postulated for the discharge of oxide ions on graphite at much higher temperatures. ${ }^{27}$ In this case, at low and high cds the reaction mechanism also involves thermal reactions as rate-determining steps. We therefore conclude that under Temkin conditions there are various possibilities equally probable for interpreting the kinetics of the electrode reaction, which offers the same ambiguity already stressed for other electrode reactions interpreted in terms of a Temkin isotherm, such as the evolution and dissolution of oxygen on platinum in aqueous solutions. ${ }^{28}$ However, the important conclusion is that whatsoever the first- or second-order process, the kinetics of the electrode reaction is determined by a thermal reaction.

\section{The likely mechanism for the formation of $\mathrm{CO}$}

There are at least two possibilities to interpret the formation of CO. The first one is the interconversion of $\mathrm{CO}_{2}$ to $\mathrm{CO}$ on the graphite surface promoting graphite oxidation by means of a reaction like that expressed by the Boudouard equilibrium.29 However, from the analysis of thermodynamic and kinetic data related to the thermal oxidation of carbons, ${ }^{30,31}$ it seems unlikely that in the temperature region of the present experiments any appreciable interconversion according to the Boudouard equilibrium takes place. Furthermore, the variation of $\mathrm{CO}_{2}$ diagram with different types of carbons, the approximately fixed value of the $\mathrm{CO}_{2} / \mathrm{CO}$ ratio obtained either in the slow or in the fast decomposition and the appearance of only one reaction product when the starting material is a previously oxidized carbon, sustain the idea that even in the thermal reaction no appreciable interconversion of reaction products occurs. ${ }^{31}$ The ratio $\mathrm{CO}_{2} / \mathrm{CO}$ in the electrochemical reaction indicates that $\mathrm{CO}_{2}$ is the main product, as is also the case, for instance, for the thermal oxidation of Spheron-6 in the temperature range from 25 to $400^{\circ} \mathrm{C}$. $^{31}$ 
Another possibility, which is supported by the existence of two reaction products at a nearly constant ratio, is that $\mathrm{CO}$ comes from the thermal decomposition of any oxidized intermediate formed during the electrochemical reaction, giving a further support to the presence of at least two oxidized intermediates on graphite. This reaction being restricted, as in the case of $\mathrm{CO}_{2}$ formation, only to edge atoms of graphite, ${ }^{32}$ would explain why the anodic efficiency for $\mathrm{CO}_{2}$ formation is less than $100 \%$.

The participation of different oxidized intermediates is related to the existence of different types of oxides on the graphite surface. It was shown ${ }^{33}$ that at temperatures between 25 and $400^{\circ} \mathrm{C}$ the peripherical fragments of carbon involving one or two atoms can react with oxygen forming lactonic rings, while structures of carbonyl type exists on adjacent carbon atoms. From the study of chemisorption of oxygen on very clean carbon surfaces, ${ }^{20}$ it was concluded that the adsorption of oxygen atoms on more reactive sites may lead to the formation of lactonic groups, while those adsorbed on adjacent carbon atoms forms carbonyl groups. According to this structure, carbonyl groups under certain conditions, for example during electrochemical reaction, may lead to anhydride group formation, which by further thermal decomposition at intermediate temperature, would yield $\mathrm{CO}$ and $\mathrm{CO}_{2}$, according to the reaction path recently proposed by Coltharp and Hackerman for the thermal reaction. ${ }^{31}$

The existence of various types of adsorption sites of different energy on carbons has been the subject of much discussion. They have been postulated to explain the thermal reaction of graphite with oxygen as well as other oxidation reactions on carbons. ${ }^{34-41}$ Graphite electrode oxidation in cryolite melts has also been explained by the existence of stable and metastable complexes formed between graphite and oxygen. ${ }^{42-44}$

\section{The activation energy of the reaction}

The experimental activation energy for the electrochemical oxidation of graphite in bisulphate melts is high as compared to the activation energy values found frequently in electrode processes, but the figure is not surprising when it is compared with the experimental activation energies obtained in the thermal oxidation of graphite to volatile compounds, between 250 and $450^{\circ} \mathrm{C}$, which are of the same magnitude. These figures are dependent on the number of existing defects and on the degree of graphitization of the sample. For highly graphitized carbons it lies between $\mathbf{4 0}$ and $50 \mathrm{Kcal} / \mathrm{mol}^{45-50}$ The more probable value recently given is $44 \mathrm{kcal} / \mathrm{mol} .{ }^{47}$

The coincidence of the experimental activation energies for the thermal and electrochemical oxidation of graphite within the same temperature range is another indication that the kinetics of these processes are closely related.

Acknowledgement-This work was in part supported with funds from the Consejo Nacional de Investigaciones Cientificas y Técnicas of Argentina.

\section{REFERENCES}

1. A. J. Arvía and W. E. TriacA, Electrochim. Acta 11, 975 (1966).

2. A. J. ArvíA and W. E. TriacA, An. Asoc. quim. Argent. 56, 33 (1968).

3. A. J. Calandra and A. J. Arvia, Electrochim. Acta 11, 1173 (1966).

4. R. Piontell, G. Stermeim and F. Fumagalli, Ricerca scient. 28, 160 (1958).

5. H. J. Vandenbroele and A. J. Arvía, An. Asoc. quim. Argent. 55, 21 (1967).

6. W. E. TriacA, O. Solomons and J. O'M. Bockris, Electrochim. Acta 13, 1949 (1968).

7. A. J. ARviA and J. B. De CusminskY, Trans. Faraday Soc. 58, 1019 (1962).

8. A. J. Arvia, A. J. Calandra and H. A. Videla, Electrochim. Acta 13, 167 (1968). 
9. A. J. Arvin, A. J. Calandra and H. A. Vimela, An. Asoc. quim. Argent. 54, 143 (1966).

10. P. L. WALker, JR. F. Rusinko, JR., and L. G. Austin, Advances in Catalysis, XI, p. 133. Academic Press, New York (1959).

11. E. Gilleadi and B. E. Conway, Modern Aspects of Electrochemistry, III. Butterworths, London (1964).

12. H. P. Boerm, Advances in Catalysis, XVI, p. 179. Academic Press, New York (1966).

13. H. HARker, C. JACkson and W. F. K. WyNNe-Jones, Proc. Roy. Soc. A262, 328 (1961).

14. W. Lobenstein and V. R. Dietz, J. phys. Chem. 59, 481 (1955).

15. N. R. Laine, F. J. VAstola and P. L. Walker, JR., J. phys. Chem. 67, 2030 (1963).

16. W. J. Thomas, Carbon 3, 435 (1966).

17. B. E. ConwaX and P. L. Bourgault, Trans. Faraday Soc. 58, 593 (1962).

18. B. E. Conway, Theory and Principles of Electrode Processes. Ronald Press, New York (1965).

19. J. J. TletJen, P. L. WAlKer, JR. and L. G. Austin, Chemistry and Physics of Carbon 1, p. 327. Dekker, New York (1966).

20. P. J. Hart, F. J. Vastola and P. K. Walker, JR., Carbon 5, 363 (1967).

21. H. L. RuLeY, Fuel 24, 8 (1945).

22. D. Dumas and G. Brenet, C.r. hebd. Sêane. Acad. Sci. Paris, 265C, 1395 (1967).

23. S. I. RempeL, Anodic Processes in the Electrolysis of Aluminum. Scientific Ed. Sverdlosk, U.S.S.R. (1961).

24. E. Papirer, J. B. Donnet and A. Schutz, Carbon 5, 113 (1967).

25. B. E. ConWAY and E. GILeAd, Trans. Faraday Soc. 58, 2493 (1962).

26. H. Boudart, J. Am. chem. Soc. 74, 3556 (1952).

27. R. G. ChuRILYAEV, Trudy. L.P.I. 272, 79 (1967).

28. A. Damunovic, A. Dey and J. O'M. Bockris, Electrochim. Acta 11, 791 (1966).

29. A. Borucka, Electrochim. Acta 13, 295 (1968).

30. S. ERgun, J. phys. Chem. 60, 480 (1956).

31. M. T. Coltharp and H. HACkerman, $J$. phys. Chem. 72, 1171 (1968).

32. G. R. Hennig, Proc. Fifth Conf. on Carbon 1, 143 (1962).

33. R. N. SMTth, D. A. Young and R. A. SMrTH, Trans. Faraday Soc. 62, 2280 (1966).

34. R. H. Savage, Ann. N.Y. Acad. Sci. 53, 862 (1951).

35. C. A. Coulson, Proc. Fourth Conf. on Carbon, p. 215. Pergamon Press, Oxford, (1960).

36. J. Nagle and R. F. Strickland-Constable, Proc. Fifth Conf. on Carbon 1, 154 (1962).

37. L. Bonnetan,, J. Chim. phys. 58, 34 (1961).

38. J. M. Thomas and E. E. Huohes, Carbon 1, 209 (1964).

39. R. M. BARRER, J. colloid. Interface Sci., 21, 415 (1966).

40. B. R. Purr, S. C. Anand and N. K. Sandley, Indian J. Chem. 4, 310 (1966).

41. G. R. Hennig, Carbon 3, 107 (1965).

42. T. G. Prarson and J. Waddington, Discuss. Faraday Soc. 1, 307 (1947).

43. H. STERN and G. T. Holmes, J. electrochem. Soc. 105,478 (1958).

44. R. Prontelli, B. Mazza and P. Pedeperre, Electrochim. Acta 10, 1117 (1965).

45. M. Shelef and P. L. Walker, JR., Carbon 5, 93 (1967).

46. A. R. UbBelohme and F. A. LeWIs, Graphite and its Crystal Compounds, p. 163. O.U.P., London (1960).

47. S. J. GreGg and R. F. S. Tyson, Carbon 3, 39 (1965).

48. J. SerPINET, Thesis, Nancy (1956).

49. G. BlyHolder and H. Eyring, J. phys. Chem. 61, 682 (1957); 63, 1004 (1959).

50. J. Duval, J. Chim. phys. 58, 3 (1961). 